\title{
Oil Spills-Are There Any Sustainable Remedies?
}

\author{
Saravanan D* and Vijayasekar $\mathbf{R}$ \\ Department of Textile Technology, Bannari Amman Institute of Technology, India \\ *Corresponding author: Saravanan D, Department of Textile Technology, India

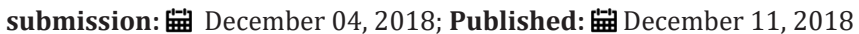

\section{Opinion}

Oil spills happen in the sea and land, causing serious damages to the environment. Crude oil is a mixture of gas, naphtha, kerosene, and residuals, which cause health hazards if consumed by any life forms or when it is accidentally spilled. Spills of very low quantities to more than a million gallons of oils have been reported in the past, whose impacts are still evident to various elements associated in those environments. Many anthropogenic reasons including offshore drilling and production operations, oil spills from ships / tankers and natural seeps are the major sources of oil spills.

Oil spills at sea are generally much more damaging than those on land, since they can spread hundreds of nautical miles in a thin continuous oil slick, which can also cover beaches with a coating of oil. The direction of wind, difficult to predict in the oceans, which can move relatively longer distance, is the major concern and in turn extends the extent of problems faced in remedial measures. Though it is often difficult to estimate the quantity of spill exactly, by observing the thickness of the film of oil and its appearance on the surface of the water, it is possible to estimate the quantity of oil spilled. If the surface area of the spill is also known, the total volume of the oil can be calculated, to a larger extent.

Oil spills may impact the environment in terms of physical smothering of organisms, chemical toxicity, ecological changes and many other indirect effects. As the oil on the sea surface evaporates, different organic compounds enter the air from the oil slick. Oil spills kill marine mammals such as whales, dolphins by clogging their blowholes, making difficult for them to breathe properly. Oil destroys the insulating ability and water repellency of fur-bearing mammals, thus exposing these creatures to the harsh conditions. Without the ability to repel water and insulate from the cold conditions, birds and mammals die from hypothermia. Larval fish, plankton, seaweed, mussels, oysters, turtles, algae, and fish, are all considerably affected by the oil spill in the marine environment. Oil also clogs up the gills of the fish that live there and suffocates them. Common problems observed among the nearby habitats include behavioral changes, blindness, damages to internal organs, spread among the habitats, sores and stress. Losing tons of oil, which is not only a natural source of energy but also a depleting source, has a severe impact on a country's economy that leads to severe setback. Prevention measures are focused to avoid the release of oils into the environment and also based upon early warning and provide details about the breadth of oil slick, popularly known as 'hot spots' to initiate clean-up processes.

There are no official records related to the incidents of big oil spills in the sea, in the early 1500 s spill due to natural seep has been reported near California. Later, oil spills were reported in various locations at different time frames, near US during 1859 near Pennsylvania and 1889 Los Angeles. International Tanker Owners Pollution Federation has tracked 9,351 accidental spills since 1974 and there have been 18 major oil spill incidents, involving the total quantities in excess of 100,000 tonnes of oil spills.

When different kinds of oils enter the sea, physical, chemical and biological reactions start with different rates. After a few hours of spill, because of the effects of wind, wave actions and turbulence of water, the slicks begin to break up and, form narrow bands or windrows parallel to the wind direction and disintegrates into fragments that spread over larger areas. Turbulence in sea water and mixing oil and water result in emulsification of oil-in-water, also known as mousse. Some of the physio-chemical reactions that might happen to the oil in water include weathering, spreading, evaporation, dispersion, emulsification, dissolution, oxidation, sedimentation and biodegradation.

It is critical to contain the spill as quickly as possible, in order to minimize danger to human beings and to the environment. Cleaning up of oil spill is not an easy task and factors including quantity and viscosity of oil, temperature of water (influencing evaporation and biodegradation), type of shoreline and beaches other factors relevant to the affected sites need to be considered and might take months or years to complete the clean-up.

Techniques used in order to reduce oil spill consequences include containment techniques - used to limit the spread of oil (predominantly with booms) and to allow for its recovery, removal or dispersal, and clean-up techniques-booms used in recovering oil, skimmers, sorbents, dispersants in addition to other alternative systems like in-situ burning and biological methods. Alternately, these techniques are also categorized into physical techniques, chemical techniques and biological techniques. Often the response involves a combination of all these approaches. 
Oil biodegrades over a period of time into harmless substances such as fatty acids and carbon dioxide. The biodegradation can further be facilitated by the addition such microorganisms into the spilled environment and micro-nutrients that support the growth of microorganisms, i.e. bioremediation or using suitable genetically modified organisms.

Though different options are available to treat the oil spills chemically, they tend to leave unwanted effects like creating air pollution in the form of $\mathrm{SO}_{x^{\prime}} \mathrm{No}_{x^{\prime}}$ carbon residues and concentrated heavy pollutants in the sea environment. Though application of chemical dispersants facilitate the formation of smaller droplets of oil readily available for microbial digestion, it can affect marine organisms like deep water corals and sea grass.

In physical methods, boomers and skimmers are helpful in spill containment in good weather conditions and concentrate the spill within a particular area but not so effective in rough sea with higher and speedy waves. However, innovative solutions are obtained in containing, controlling and eliminating the oil spills using sorbent substances in the form of powders, fibres, foams and fabrics. Sorbents remove oily substances from the spilled areas by adsorption as well as absorption (solidifiers) by wicking through capillary action. Adsorbents allow oil to penetrate into pores of the materials they are made of, and hence these materials can be engineered to suit the requirements of the clean-up process. On completion of the task, saturated adsorbents are disposed through incineration or landfilling under safe conditions. Although the oil saturated adsorbents are not sold in the market openly, they can potentially be used as a fuel material. Textile materials in the form of fibres, woven, nonwoven and composites are recommended in the clean-up process to remove the oil spills. Compared to biological and chemical processes, textile materials as adsorbents offer wide range of benefits which include - most fibres are obtained from renewable sources, cheaper alternative, degree of adsorption can be engineered, facilitates safe disposal after clean-up and does not leave adsorbing material in the spot.

Many plants based cellulosic fibres like cotton, kapok, nettle, coir, kenaf, luffa and straw are recommended to larger extents due to inherent advantages associated with these fibres in terms of voids, amenable surface areas and extent of amorphous regions present in these fibres, which all together can contribute to oil spill clean-up. Though these fibres can be converted into different structural forms, recommendations of nonwoven for clean-up process appears to be predominant due to high air (void)-fibre ratio that can be altered as per the demands. Polypropylene, the well-known synthetic fibre, is widely used for producing nonwoven materials for clean-up processes while nylon and silica based synthetic fibres are also used in such efforts. However, enormous amounts of research works are being carried out in the field of sorbents using different materials and mechanisms to maximize the removal of spills and reduce the impact. Since we have proven concepts and theories available for separation of liquid-liquid and liquid-solid, these adsorbents are likely to draw more attention in the coming years as far as clean-up processes are concerned and needless to state, structural assemblies of fibres would become high value proposition in the clean-up process and restoration of environmental conditions.
Creative Commons Attribution 4.0 International License

For possible submissions Click Here

\section{Submit Article}

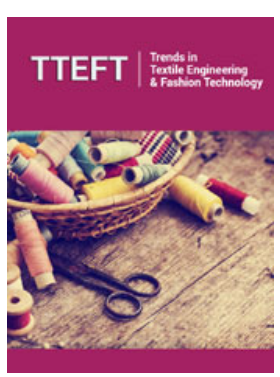

Trends in Textile Engineering \& Fashion Technology

\section{Benefits of Publishing with us}

- High-level peer review and editorial services

- Freely accessible online immediately upon publication

- Authors retain the copyright to their work

- Licensing it under a Creative Commons license

- Visibility through different online platforms 